\title{
Rights of patients in developing countries: the case of Turkey
}

\section{E Aydin}

J Med Ethics 2004;30:555-557. doi: 10.1136/jme.2003.005819

Patient rights are universal values which we have to adopt. It is not so easy, however, to put such values and principles into effect. As approaches and attitudes differ from individual to individual, from society to society, and from country to country, a uniform application of these values is difficult. If we want to reach a general conclusion about the status of patient rights in the world as whole, we should examine the situation in individual countries. As far as Turkey is concerned, we can say that, although the idea of patient rights is accepted in principle, patient rights have yet to be adequately implemented.

$\mathrm{T}$ he most important regulation in Turkey on patient rights is the statute of patient rights which came into effect in 1998. ${ }^{1}$ Although the statute of deontology, issued in 1960, which concerned the principles involved in the relation between the physician and the patient, did not specifically mention patient rights, it did address some issues relating to patient rights. ${ }^{2}$ During the preparation of the statute on patient rights, the Ministry of Health did not find it necessary to consult either those in academic circles or the Turkish Medical Association. ${ }^{3}$ The statute of patients, rights came into effect in 1998. The statute states that patient rights must be considered as an extension of basic human rights to the field of health services. Patients must have the right to make use of all health services according to their need, including preventive measures and activities designed to encourage healthy living, in accordance with the principles of justice and fairness. This right also means that it is the responsibility of institutions offering health service, and of their personnel, to serve patients without violating the principles of justice and fairness. In the provision of health services, all patients are to be considered equal irrespective of their race, language, religion or creed, sex, political views, philosophical beliefs, and economic and social status. Health services are to be designed and organised in such a way that they are easily accessible to all. ${ }^{1}$

According to the statute, everybody has the right to feel safe and secure in health institutions. Despite this principle being outlined in the statute, this is not the case in practice. Health institutions take the measures necessary to enable patients to fulfil their religious rituals and duties, in so far as they can. The patient has the right to choose the health institution he or she wants, provided this does not breach the regulations, and to make use of the services offered there. The patient may change the health institution where he receives treatment as long as it is in accordance with the system of referral determined by regulations. This change should not, however, harm or endanger the patient's health. The referring institution must send the necessary information to the institution to which the patient is being referred. The patient has the right to have people accompanying him in so far as this is possible given the institution's facilities. ${ }^{1}$
The patient has the right to be informed about the identities, duties, and titles of the physician and the other health workers. The patient also has the right to choose the staff who will attend to him, to change his attendant physician and also to ask for other physicians to be consulted without violating the regulations. Apart from this, where the health service provided is inadequate and/or poor, the patient has the right to demand that priority be determined according to objective medical ethics. The patient may receive information from a physician other than the one who is treating him. The patient has the right to ask for diagnosis, treatment, and care in accordance with state of the art medical knowledge and technology. The patient has the right to examine his or her records and to demand a copy. ${ }^{1}$

The results of some studies show, however, that there is a marked discrepancy between physicians' respect for patient rights in principle, and the actual application of these principles in practice. Although physicians state that they respect patient rights, the replies of the patients do not corroborate this claim. The majority of the patients state that their rights are not respected in practice. ${ }^{4}$ In a study conducted in a university hospital, the following were acknowledged as patient rights by physicians and nurses. The right to:

- know the name of the physician and the nurse;

- to be given information on the system of working;

- be informed about care and treatment;

- be informed about treatment options and risks;

- be asked for their opinion before treatment;

- refuse treatment;

- have their privacy protected;

- be informed beforehand if they are being considered for inclusion in trials;

- be informed about both diagnosis and prognosis;

- be informed about the health services they will need after discharge;

- be informed about hospital bills and conditions of payment;

- be informed about the possibility of communication with other health institutions;

- respectful care, and

- ask for the best possible service the institution can currently provide. ${ }^{5}$

Informed consent, the confidentiality of information about the patient, and informing the patient of the truth are among the points addressed in the statute of patient rights. These can be outlined as shown below.

\section{INFORMED CONSENT}

The convention of getting permission from the patient before a surgical intervention is based upon a law issued in $1928 .{ }^{6}$ 
Yet, the patient's right to informed consent and to participate in the decision making process are recent concepts. The statute on patient rights considers informed consent to be one of the basic values of the relationship between the physician and the patient. According to this statute, personal rights and the physical integrity of a person cannot be violated except in emergencies and other situations stipulated by law. The patient has the right to ask for verbal or written information about his health status; medical interventions; their probable benefits, risks and drawbacks; alternative treatment methods; possible consequences of refusing treatment, and the course and the prognosis of the disease. This information may be demanded by the patient him/herself or by the guardian in cases where the patient is not competent. A patient may authorise someone else to receive information in his name. ${ }^{1}$

When informing the patient, even if the patient is not competent, his participation in the decision making process is to be encouraged as far as possible. If it is certain that the patient will benefit from the procedure and the legal guardian does not give permission, the courts may intervene. Where there is a dispute it is up to the court to decide whether the patient will be included in a study.

When the patient is being informed, the situation must be explained in clear and intelligible language. Medical terminology should be avoided as much as possible. The psychological status of the patient should be taken into account and polite expressions must be used. If the patient is a foreigner, an interpreter can be used if necessary. If the patient does not want any information to be given to himself or to his family, this wish should be respected. ${ }^{1}$

In addition, the patient may withdraw informed consent. This is allowed even if the procedure has already started, as long as there are no medical contraindications. The patient may refuse the treatment recommended by the physician. The patient also has the right to ask for the interruption of any treatment procedure that has already started. The possible consequences of this should be explained to the patient, or to his legal representative or relatives, and this should be certified by a written document. If this patient later chooses to consult the physician he had previously rejected, his previous decision cannot be used against him. ${ }^{1}$

A study carried out on surgeons found out that they were concerned about giving patients information in case this led the patients to refuse treatment. ${ }^{7}$ It was established in another study that although the patients wanted to be informed, they preferred the decision about treatment to be taken by the physician. ${ }^{8}$ It must be said that in terms of patient rights this is not a situation which is to be welcomed.

\section{CONFIDENTIALITY AND PRIVACY}

According to the statute of patient rights, it is essential to respect the privacy of the patient. The patient has the right to make use of health services in a manner consistent with his personal values. The confidentiality and privacy of both the patient and his family cannot be violated except in cases determined by law or where medical intervention is necessary to save life. The patient may explicitly demand the protection of his privacy. All medical interventions must be carried out in a way that does not impinge upon the privacy of the patient. Likewise, procedures of examination, diagnosis, and treatment must be conducted with as much confidentiality as can reasonably be expected. There must be no interference with the personal and family life of the patient unless it is medically indicated. The patient must be allowed to have someone close to him with him, unless this is medically contraindicated. During medical interventions, people who are not involved with administering treatment should not be nearby. Death does not provide an excuse for the violation of confidentiality and privacy. ${ }^{1}$

According to the regulations, if it is necessary to have people in attendance who are not directly involved with the treatment during medical intervention, the patient's consent must be obtained beforehand or during treatment. Even if the patient gives consent, in situations where there is a complete violation of personal rights, or their excessive restriction or their transfer to others, the ones who make public the confidential information remain legally responsible. Giving information which may harm the patient, without any legal and ethical grounds, is cause for legal and penal liability. In circumstances of investigation and training, the patient's personal information cannot be passed on without his consent.

\section{THE RIGHT OF THE PATIENT TO KNOW THE TRUTH}

When we consider the right of patients to know the truth about themselves in the context of regulations in Turkey, we see that this right is interpreted by physicians paternalistically. Accordingly, it is deemed legitimate to withhold information about the diagnosis from the patient in cases where it may possibly worsen the diagnosis by having an adverse effect on the morale of the patient, and when the course of the condition and prognosis is grave. Whether the patients and their relatives should be informed about the medical status of the patient is left to the judgment of the physicians. The diagnosis of an incurable disease should always be conveyed by a physician in a very tactful manner. Such a diagnosis may be reported to the family unless the patient has expressly forbidden this. Such an action will, however, be a violation of the patient's right to know the truth. ${ }^{1}$

\section{CONCLUSION}

Turkey has always tried to follow developments in the Western world. The attempt to become a member of the European Union has accelerated the efforts of Turkey in this direction. Also, many legal reforms have been made in order to adapt Turkish law to the laws of the European Union. Turkey has also signed the European Convention on Human Rights. Therefore, during the preparation of the statute of patient rights, examples of similar Western legislation have certainly been used. It is also our concern, however, that the actual putting into practice of general principles on human rights should keep pace with the issuing of legal regulations.

Correspondence to: Dr E Aydin, Hacettepe University Faculty of Medicine, Department of Medical Ethics and History, Ankara Turkey; eraydin@hacettepe.edu.tr

Accepted for publication 28 July 2003

\section{REFERENCES}

1 Hasta haklari yonetmeligi (Statute on patient rights). Offical Gazette 1998 Aug 1 (no 23420).

2 Deontoloji tuzugu (Statute on medical deontology). Offical Gazette 1960 Feb 19 (no 10436).

3 Arda B. Privacy rights of psychatric patients: a recent protocol in Turkey. Thirteenth World Congress on Medical Law. Book of Proceedings 1; 2000 Aug 6-10; Helsinki, Finland.

4 Atac A, Filizkaya N. Hekim-hasta iliskisi ve hasta haklari ile ilgili bir anket calısmasi. (A questionnaire on the relation between patients and physicians and patient rights). In: Pelin SS, Arda B, Ozcelikay G, et al. Proceedings of the Third Medical Ethics Symposium; 1998:7, Oct 23-25; Ankara, Turkey.

5 Zencir GG, Erdal E, Zencir M. Hekim ve hemsirelerin hasta haklari konusunda tutumlarinin incelenmesi. (Investigation of the attitude of patients and physicians to the rights of patients). In: Ersoy N, Gundogmus UN, eds. Proceeding of the First National Medical Ethical Congress; 1999 Jun 9-11; Kocaeli, Turkey. 
6 Tababet ve suabati san'atlarinin tarzi icrasina dair kanun. (Law on the practice of medical arts). Official Gazette 1928 Apr 14 (no 863).

7 Ersoy N. Klinik etigin onemli bir sorunu: aydinlatilmis onam. (An important problem of clinical ethics: informed consent) $T$ Klin J Med Ethics

1994;2:131-6.
8 Civaner M, Terzi C. Hastanin kendi kaderine tayin hakki: Aydinlatilmis onam. (The right of the patient to make decisions regarding his treatment: informed consent). In: Arda B, Akdur R, Aydin E, eds. Proceeding of the 2nd National Medical ethical Congress; 2001, Oct 18-20;

Kapadokya, Turkey. 